\title{
O MARCO DO JAURU: A CONSTRUÇÃO DE UM SABER SOBRE O MONUMENTO/A MONUMENTALIDADE
}

\author{
WELLITON MARTINS BINDANDI ${ }^{1}$, OLIMPIA MALUF-SOUZA ${ }^{2}$
}

Programa de Pós-Graduação em Linguística - Universidade do Estado de Mato Grosso Av. Santos Dumont, Cidade Universitária - 78200-000 - Cáceres-MT - Brasil

welliton.m.bindandi@gmail.com, olimpiamaluf@gmail.com

\begin{abstract}
Resumo. O presente estudo procura compreender os processos de produção de sentido do monumento, do arquivo, e assim entender seu sentido monumental, o de monumentalidade. Para isto, tomamos em análise o Marco da Jauru na cidade de Cáceres-MT e, assim, entender os processos de significação que transformam construções, que até o tombamento considerado comuns, em monumentos. Portando, buscamos compreender o processo de produção de sentido de monumentalidade na perspectiva da Análise de Discurso proposta por Pêcheux, na França, e desenvolvida por Orlandi, no Brasil.
\end{abstract}

Palavras-chave: discurso; monumento; monumentalidade.

\begin{abstract}
This study aims to understand the production processes of meanings of monument, archive, and comprehend its monumental sense, of monumentality. For this, we analyzed the Marco do Jauru in Cáceres-MT, and then understand the signification processes that transform buildings, considered ordinary in its falling, in monuments. Therefore, we want to understand the production process meaning of monumentality from the discourse analysis' perspective proposed by Pêcheux in France and developed by Orlandi in Brazil.
\end{abstract}

Keywords: speech; monument; monumentality.

\section{Introdução}

O presente trabalho resulta de uma pesquisa que desenvolvemos no Mestrado sobre os sentidos atribuídos à cidade de Cáceres-MT e seus moradores, a partir de seus monumentos e patrimônio histórico tombado pelo poder público, o IPHAN. Desse modo, interessou-nos compreender o patrimônio como lugar de memória, ou seja, enquanto processo de constituição da cidade, que coloca em funcionamento modos de constituição dos sujeitos e dos sentidos.

\footnotetext{
${ }^{1}$ Doutorando em Linguística pela Universidade do Estado de Mato Grosso (UNEMAT-Cáceres/MT). http://lattes.cnpq.br/5222749754528877.

${ }^{2}$ Doutora em Linguística pela Unicamp. Professora do Programa de Pós-Graduação em Linguística da Universidade do Estado de Mato Grosso (UNEMAT-Cáceres/MT). http://lattes.cnpq.br/9974266213083899.
} 
Para tais propósitos, propomo-nos a discutir sobre o saber monumental das arquiteturas do centro histórico da cidade, tomando-as como monumento, ou seja, como objeto simbólico, que produz, por consequência, os modos de significação da cidade de Cáceres. Tomamos, dessa maneira, o saber monumental como o processo que desloca sentidos de um monumento ou construção, tidos até um dado acontecimento discursivo como comuns, para os sentidos de monumental/monumentalidade. Pêcheux (1997, p. 17) aponta o acontecimento discursivo, como sendo o "[...] ponto de encontro entre uma atualidade e uma memória", pois, para o autor, a correlação entre um fato e a forma em que foi entendido, propagado e circulado, atualiza-se e se mantém sempre presente na memória coletiva.

Para este artigo, trazemos uma abordagem teórica da passagem de sentidos corriqueiramente atribuídos à construção/documento/monumento para os sentidos de monumentalização/monumentalidade. Assim, para dar visibilidade a esse movimento, colocamos em análise um monumento na cidade: o Marco do Jauru.

\section{Um saber sobre o monumento/a monumentalidade}

Como dizer do monumento e da monumentalidade na perspectiva da Análise de Discurso? Como a monumentalidade se apresenta a nós enquanto um conceito que reverbera e que produz sentidos outros, discursividades outras, uma vez que se constitui e se instaura pela ordem do simbólico?

O que propomos pensar, a partir dessas questões, é como o documento, o trivial, o ordinário do sentido, a evidência se constitui em monumento, em monumental, em monumentalidade.

Ao dizermos da monumentalidade - de um objeto, de uma palavra, de uma edificação - estamos pensando-a enquanto uma textualização simbólica, que carrega, que significa, que materializa duas ordens de real: da língua e da história. Então, na arquitetura da cidade, o que se coloca como monumentalidade já traz em si o caráter da incompletude e da contradição. Assim, podemos afirmar que, na monumentalidade, pelo real da língua, consideramos uma impossibilidade de dizê-la, visto que a língua(gem) é incompleta e carrega algo de perdido, de interditado, de impossibilitado ao sujeito; e, pelo real da história, o seu funcionamento é de uma contradição que não se resolve, que não se explica, que não se acomoda, que não se acorda por nossas vontades, o que marca a impossibilidade do desejo de resgate, pelo poder público.

Dessa maneira, ao dizermos da monumentalidade, estamos considerando, de antemão, a nossa impossibilidade de tudo dizer, de tudo acordar, pois o real, na perspectiva de Lacan, comungada por Pêcheux (1997, p. 43) é algo que não cessa de se inscrever, não cessa de nos interpelar, mas que estamos impossibilitados de dizer, pois:

interrogar-se sobre a existência de um real próprio às disciplinas de interpretação exige que o não-logicamente-estável não seja considerado a priori como um defeito, um simples furo no real. [...] entendendo-se o "real" em vários sentidos - possam existir um outro tipo de real diferente dos que acabam de ser evocados, e também um outro tipo de 
saber, que não se reduz à ordem das "coisas-a-saber" ou a um tecido de tais coisas. Logo: um real constitutivamente estranho à univocidade lógica, e um saber que não se transmite, não se aprende, não se ensina, e que, no entanto, existe produzindo efeitos.

O real, da língua e da história é, pois, algo vivido, algo simbolizável, mas de tal modo incompleto e contraditório que não podemos dizê-lo a não ser pela(s) ideologia(s) que a constitui. Então, só a ideologia é capaz de nos permitir compreender as formas de simbolização do caráter monumental.

A palavra, o objeto, o monumento são tomados como processos de simbolização, como representações simbólicas que conformam toda e qualquer materialidade simbólica. É o simbólico que dá à palavra e às construções urbanas o seu caráter monumental, que é representado por uma interpelação, um modo de individuação, devido ao caráter particular que cada posição-sujeito atribui ao objeto ao ser interpelado por uma dada ideologia. Dizer, pois, do caráter particular do objeto é falar de uma inscrição na memória do dizer, na formação discursiva que, sendo uma constituição histórica, é memorizada por um sujeito em particular. Particular porque, ao dizer do vivido, da memória, o sujeito pode se constituir como lugar de resistência, inscrevendo-se em novos e diferentes modos de dizer. Pêcheux (1988, p. 160) compreende a formação discursiva como "[...] aquilo que, numa formação ideológica dada, [...] determina o que pode e deve ser dito [...]" (grifos do autor).

É esse funcionamento que coloca o dizer como parafrástico e/ou polissêmico, uma vez que no gesto mesmo da repetição, os sentidos novos se colocam, atualizando, por consequência, modos diferentes, modos outros de se inscrever no interdiscurso para dizer do objeto, da coisa, do vivido. É, pois, nessa direção que dizemos do particular, do diferente, do novo, ou seja, enquanto o modo pelo qual o sujeito se inscreve na memória do dizer para significar o monumento, a arquitetura e, ao mesmo tempo, significar-se. Pêcheux (op. cit., p. 162) define o interdiscurso como o "[...] todo complexo com dominantes das formações discursivas [...] submetido à lei de desigualdade-contradiçãosubordinação que [...] caracteriza o complexo das formações ideológicas", em outras palavras, algo que se constitui como uma memória discursiva, como um "[...] acontecimento a ler, [que] vem reestabelecer os implícitos [...] de que sua leitura necessita: a condição legível em relação ao próprio legível" (PÊCHEUX, 1999, p. 52).

Por outro lado, o dizer carrega também um modo social, pois se trata de um encadeamento estabelecido pela história, pelo modo como os sujeitos a significaram/significam e, com isto, se dão a significar. Nessa direção, todo dizer é um movimento contínuo e aberto que vai se fazendo e se refazendo no jogo discursivo, e é nesse movimento - que não para, que se refaz sempre, que não cessa de abrir-se aos sentidos cristalizados e aos novos - que o real da língua e o da história interditam o acesso a todo o sentido, fazendo escapar daí o que se constitui e que se institui para além do objeto empírico, aquilo a que, no nosso recorte, estamos chamando de sentido monumental/monumentalidade.

O caráter particular do objeto interpretado diz do que é próprio, peculiar a cada sujeito ao ser interpelado por uma dada ideologia e não por outra, e o social diz dos modos como os sentidos cristalizados, os pré-construídos (o que já foi dito e esquecido e que se cristalizou na memória do dizer) determinam nos modos de interpretação do monumento, da arquitetura, enfim, do patrimônio histórico. Trata-se, nas palavras de Orlandi (2001, p. 
31), do "[...] saber discursivo que torna possível todo dizer e que retorna sob a forma do pré-construído, o já-dito que está na base do dizível, sustentando cada tomada da palavra".

Partimos do entendimento de que o monumental/a monumentalidade funciona como um documento, pois, através da edificação monumental, vemos em funcionamento sentidos que circunscrevem o objeto à ordem do simbólico, portanto, acatando tanto o real da língua quanto o da história para significar.

Segundo Rodrigues (2009, s/p), a “[...] monumentalidade atua na dimensão do simbólico, dando visualidade, representando e valorizando as ideias, ações e concepções daqueles que a utilizam". Em outras palavras, instaura-se, sobre o monumento, uma dimensão simbólica, que lhe confere o sentido de monumentalidade, de grandeza. É, então, pela ordem do discurso que o sentido de monumental/monumentalidade se instala, através de uma formação histórico-ideológica que lhe confere/atribui esses sentidos e não outros. Ou seja, é o atravessamento da ideologia que produz ao monumento modos de constituição do caráter monumental/de monumentalidade.

Para nosso estudo, a arquitetura do centro da cidade, enquanto documento ${ }^{3}$ tornado monumento, ou seja, a palavra, a formulação sobre esse espaço da cidade apresenta-se enquanto funcionamento de sentidos, enquanto discursos, ou, conforme Nora (apud Orlandi, 2010), enquanto um lugar de memória, pois, tudo que tomamos como monumental é compreendido aqui como objeto simbólico, isto é, tomado como um discurso, que fala com outros, que produz outros modos de dizer, que constituem os sentidos.

Foucault (2008, p. 157), ao explicar sua arqueologia, afirma que

[...] não trata o discurso como documento, como signo de outra coisa, como elemento que deveria ser transparente, mas cuja opacidade importuna é preciso atravessar frequentemente para reencontrar, enfim, aí onde se mantém à parte, a profundidade do essencial; ela se dirige ao discurso em seu volume próprio, na qualidade de monumento. (grifo do autor)

Nessa direção, o autor diz da história enquanto um funcionamento que produz sentidos, pela ordem do simbólico:

[...] a história é o que transforma os documentos em monumentos e que desdobra, onde se decifravam rastros deixados pelos homens, onde se tentava reconhecer em profundidade o que tinham sido, uma massa de elementos que devem ser isolados, agrupados, tornados pertinentes, inter-relacionados, organizados em conjuntos. (FOUCAULT, 2008, p. 8)

Para Orlandi (2003), todo dizer se constitui através da memória, assim pelo interdiscurso a memória se faz presente, tanto a discursiva quanto a de arquivo. A autora define, então, o que concebe como memória de arquivo, ou seja, aquela que representa o

\footnotetext{
${ }^{3}$ Estamos tomando como documento os prédios e monumentos da cidade de Cáceres-MT que, embora o IPHAN os tome como documentos históricos, são considerados por nós como materialidades que, instituídas por uma dada ordem simbólica, funcionam pelos sentidos de monumental/monumentalidade.
} 
discurso documental, a memória institucionalizada, a que fica arquivada em nossas instituições:

No arquivo, o dizer é documento, atestação de sentidos, efeitos de relações de forças. Se no interdiscurso há o que se deve dizer mas também o que se pode dizer e mesmo a possibilidade de se dizer o que é irrealizado, o arquivo repousa sobre o realizado, menos sobre o que pode e muito mais sobre o que se deve ser dito. No arquivo há assim um efeito de fechamento. Seu interdiscurso se estrutura pelo esquecimento, o arquivo é o que não se esquece (ou o que não deve esquecer). Se no interdiscurso fala uma voz sem nome ( $c f$. Courtine), no arquivo fala a voz comum, e de todos (embora dividida). (ORLANDI, 2003, p. 15)

Nessa direção, observamos que os monumentos materializam uma memória coletiva, portando, a análise deste objeto simbólico coloca em funcionamento uma memória histórica e ideológica acerca do que foi instituído, arquivado. São esses funcionamentos que dão ao objeto o sentido do que chamamos de monumental, pois, para nós, enquanto analistas, o documento/monumento - arquivo - tornado, pela ação do simbólico como monumental/monumentalidade, não é uma materialidade que se dá a ler por qualquer pessoa, visto que toda materialidade simbólica coloca em funcionamento uma dada memória.

Borges (2013, p. 45), ao discutir o arquivo, afirma que sua interpretação “[...] não é mera decodificação e não pode ser qualquer uma, ela é sustentada, de um lado, pela memória institucionalizada (o arquivo), e, de outro, pela memória constitutiva, isto é, pelo interdiscurso". Daí o porquê de falarmos das propriedades particulares como coletivas, como sociais, uma vez que diz de uma memória institucionalizada (a coletiva, a social) e de uma memória discursiva (a do interdiscurso), que se apresenta como uma forma particular de se inscrever para significar e interpretar.

É, então, na/pela constituição do sujeito na/pela história que se determinam os modos como os objetos, as coisas, as palavras significam. Dessa maneira, ao falarmos da inscrição do sujeito, da sua relação com o mundo, com a cidade, estamos falando de tudo aquilo que o constitui enquanto posição no dizer, enquanto posição-sujeito, pois é desse modo que ele se constitui, ou seja, que se materializa através das coisas com as quais se relaciona, com seus modos de representação e de dizer, formular. Tomar, portanto, a arquitetura do centro da cidade como material significante é dar visibilidade ao seu caráter monumental a partir do que essa monumentalidade simboliza, a partir da relação do sujeito com esse objeto, pois é só dessa maneira que podemos entrar na ordem do discurso, materializada por um emaranhado de dizeres e de sentidos que foram perpetuados, que se cristalizaram e que se deslizaram da construção dos sentidos de monumentalidade.

Tomamos a palavra "construção" para dizer do produto histórico que se constitui pelo dizer, o que, para Análise de Discurso, se estabelece como um batimento contínuo, como um produto que se instala como materialidade significante (LAGAZZI, 2010) ${ }^{4} \mathrm{e}$

\footnotetext{
4 A expressão 'materialidade significante' é empregada por Suzy Lagazzi, em suas análises com documentários e filmes (LAGAZZI, 2007), como sendo o atravessamento no material de análise de uma perspectiva materialista e, ao mesmo tempo, um resultado do trabalho simbólico sobre o significante. Nos
} 
que diz dos modos como o objeto relaciona-se com simbólico - funcionamentos que se constitui a partir do que chamamos de noção de monumentalidade.

Há uma linha tênue entre o simbólico e a monumentalidade, visto que o simbólico é a entrada principal para o saber monumental, assim, podemos afirmar que não há monumentalidade se não houver o envolvimento do simbólico, assim como não há linguagem se não houver sua representação.

A monumentalidade institui-se, então, a partir do simbólico para se instaurar como tal e para se instituir, para nós, enquanto uma noção de análise. Assim, o simbólico institui-se como a matéria prima para o sentido de monumentalidade, pois não há sentido naquilo que foge à ordem do simbólico. Dessa maneira, determinamos o sentido de monumentalidade enquanto uma categoria constituída pelo simbólico, representada por um objeto, por um documento que é monumento ${ }^{5}$, assim como o Marco do Jauru que iremos analisar.

Diante do exposto, qualquer material significante que atua na dimensão do simbólico, qualquer arquitetura que o constitui é tida como um marco histórico, uma representação única com muitos dizeres e muitas vozes que ecoaram/ecoam, que significara/significam sujeitos e sentidos, estabelecendo-se como um espaço de interpretação, que significa o único - pela memória institucional, arquivada no monumento e que significa o poder instituído - e o diferente - pela memória discursiva, que funcionando pelo batimento entre paráfrase e polissemia, entre metáfora e metonímia, entre o ordinário do sentido e o sentido cambiante, coloca em funcionamento o real da língua - a incompletude - e o da história - a contradição -, possibilitando que o sentido seja sempre outro e, ao mesmo tempo, seja o mesmo, pois pelo de monumentalização, há sentidos que se instalam e há sentidos que permanecem: aqueles que foram fixados pelo lugar de origem da cidade, no caso Cáceres-MT, uma cidade-fronteira, que estabelece uma relação histórica, visto que marca a soberania do país.

Essa é, pois, a passagem entre a arquitetura enquanto objeto físico para a arquitetura enquanto objeto simbólico, a passagem do documento/monumento ao que é da ordem do monumental/da monumentalidade. O simbólico coloca o objeto na ordem do funcionamento da linguagem, com sua incompletude, com a movência dos sentidos e dos sujeitos; o monumental, que se instaura por uma base simbólica, se estabelece por uma significação única em relação ao objeto que representa tal monumentalidade. Por exemplo, não há como qualquer outro objeto simbólico representar o que o Cristo

dizeres da autora: "a partir da definição de discurso como 'a relação entre a língua e a história', proposta por Orlandi (1996), busquei a possibilidade de ampliar seu escopo analítico, referindo o discurso como a relação entre a materialidade significante e a história. Pude, assim, concernir o trabalho com as diferentes materialidades e reiterar a importância de tomarmos o sentido como efeito de um trabalho simbólico sobre a cadeia significante, na história, compreendendo a materialidade como o modo significante pelo qual o sentido se formula" (LAGAZZI, 2010, p. 173).

${ }^{5}$ Há, no centro histórico da cidade de Cáceres monumentos (o Marco do Jauru, a Catedral) e um conjunto arquitetônico, que foi tombado pelo IPHAN. Nessa direção, o que foi tombado é tomado como um produto do trabalho humano, sócio-político, que permaneceu no tempo, estabelecendo uma ligação com o passado histórico da cidade, visto que funciona como documento, uma vez que se constitui como prova, como marca, como atestado, tanto para o IPHAN quanto para o morador local, de um outro tempo da cidade. Contudo, tomamos essas construções não apenas pelo seu valor historiográfico, pois, ao tomarmos em consideração o atravessamento dessas construções pela ordem do simbólico, elas passam a significar também por um caráter de monumental/monumentalidade. 
Redentor simboliza para o Rio de Janeiro, para o Brasil, e para o mundo, mesmo que seja feita uma réplica que mantenha as mesmas dimensões. É a esse funcionamento que um monumento, uma estátua, uma imagem ganha, funcionando de um determinado modo para um determinado povo, que estamos chamando de valor único para o social, uma vez que, ao se constituir como monumentalidade, torna-se, ao mesmo tempo, uma construção coletiva, pois a inscrição a uma determinada formação discursiva - a religiosa, no caso do Cristo Redentor - faz com que os sujeitos a respeitem e a reverenciem de um determinado modo e não de outro.

Em outras palavras, o que estamos marcando na tomada do que seja o documento/monumento/edificação erigida para os sentidos de monumental/monumentalidade é a passagem da condição de objeto empírico para a de objeto simbólico.

Podemos dizer que, colocar-se na ordem simbólico, no exemplo do Cristo Redentor, é marcar o sujeito como sendo interpelado por uma ideologia religiosa, que marca os modos como os sujeitos reverenciam, respeitam, adoram uma estátua. Esse funcionamento tem valor único, mas também coletivo, uma vez que materializa os modos particulares de cada sujeito empírico diante do objeto e, ao mesmo tempo, pelo efeito de interpelação pela ordem do simbólico, o constitui como sujeito do dizer, sujeito que marca politicamente o seu dizer, pelos modos como a ideologia o interpela e o constitui enquanto sujeito do discurso.

Nessa direção, as palavras não são indiferentes e aleatórias à inscrição nos sentidos de monumento/monumentalidade, realizadas por cada sujeito, ao formular, pois, como já dissemos, a ordem do dizer, que é convocada por qualquer objeto simbólico, se constitui na/pela trajetória histórica do sujeito, marcando sua posição no dizer.

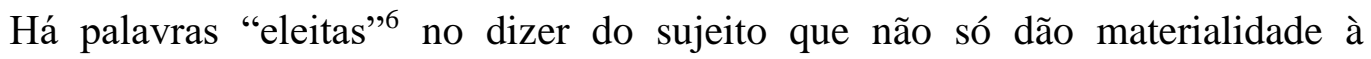
significação simbólica, mas também materializam, no seu bojo, o funcionamento de uma especificidade, que compreende os modos distintos de sujeitos diferentes se inscrevem diferentemente nos modos de interpretação de um mesmo objeto. Estamos afirmando, desse modo, que a ordem que coloca o sujeito empírico diante de objetos simbólicos, que reclamam sentidos, varia, uma vez que variam também os modos de inscrição na memória, varia a inscrição em formações discursivas, varia, enfim, a posição-sujeito. Logo, o que permanece igual, é o que é da ordem do consenso, é aquilo que se coloca como o ordinário do sentido, aquilo que se marca como evidência.

Contudo, Orlandi (2012) afirma que, mesmo na paráfrase, mesmo na ordem da repetição, o sentido novo se instala, a polissemia se coloca, pois o sujeito é também instado a se colocar na contramão das ideologias dominantes - processo que a autora chama de resistência. A autora afirma que "[...] nos processos discursivos há sempre 'furos', falhas, incompletudes, apagamentos e isto nos serve de indícios/vestígios para compreender os pontos de resistência. Os discursos - onde se articulam sistemas

\footnotetext{
${ }^{6}$ Colocamos a palavra "eleitas" em menção (entre aspas) para reforçamos o caráter de assujeitamento a que todos estamos sujeitos, pois, pela Análise de Discurso, não é o sujeito que confere sentidos aos seu dizer, ou seja, não é a sua vontade e a sua intenção que conformam os sentidos, eles estão dados pela ideologia que interpela o indivíduo em sujeito do dizer, em posição-sujeito. Dito de outro modo, o dizer constitui o sujeito e, então, não é o sujeito que constitui o dizer, o sentido, uma vez que ele é efeito no outro.
} 
significantes e ideologia - não são máquinas discursivas perfeitas" (ORLANDI, p. 213214).

Nessa direção, a autora afirma que há sentidos cristalizados, que reproduzem a cristalização e a estabilidade do dizer, através de já-ditos, de pré-construídos, mas há também a possibilidade de o sentido ser sempre outro, principalmente, na contemporaneidade em que a provisoriedade $^{7}$ acerca de quase tudo, as novas "roupagens", fazem conflitar o antigo e o moderno, o passado e o presente, colocando em questão o que estava cristalizado, regulado, instituído por uma dada forma de dizer. Assim, não é qualquer palavra, qualquer nome, qualquer formulação que se institui enquanto monumento, pois o monumento/a monumentalidade nasce e se instala a partir de fatos memoráveis, que implantam na contemporaneidade, enquanto material simbólico, algo que se instituiu em outro tempo, em outro lugar e que carrega, portanto, uma significância, mesmo que a maioria dos moradores atuais da cidade não saiba o que ali funciona.

O que vimos tentando dizer é que não há como pensar no sentido de monumental/de monumentalidade sem "ler o arquivo hoje", pois o que é o monumental/a monumentalidade a não ser aquilo que excede à memória do arquivo? Assim, é necessário fazer falar o arquivo nos dias atuais, pois o simbólico extrapola, excede o que são os fatos memoráveis, visto que, pela natureza mesma de incompletude da linguagem, há algo que é da ordem do impossível, instaurado pelo simbólico, que faz furar sempre o bojo das significações, as instituições de sentidos.

Esse funcionamento é constituído pelo jogo da língua e seu modo de significação, tornando esse lugar um conjunto de confronto e resistência. Para Pêcheux (1990, p. 17) a resistência tem a ver com:

não entender ou entender errado; não "escutar" as ordens; não repetir as litanias ou repeti-las de modo errôneo, falar quando se exige silencio; falar sua língua como uma língua estrangeira que se domina mal; mudar, desviar, alterar o sentido das palavras e das frases; tomar enunciados ao pé da letra; deslocar as regras na sintaxe e desestruturar o léxico jogando com as palavras.

Assim, o que faz falhar, o que faz furar o ritual do dizer é o fato de que há palavras, há objetos que fogem à conceitualização, uma vez que se ligam à infinitude dos desejos inconscientes como lugares não revelados à significação. É a isso que chamamos de real da língua, da impossibilidade de tudo dizer ${ }^{8}$, de monumental/de monumentalidade.

\section{A história e a ideologia de um monumento: sentidos do monumental/da monumentalidade}

\footnotetext{
${ }^{7}$ Atermamos, contudo para o fato de que, por mais inovador que seja o dizer, ele sempre se inscreve, nem que seja por oposição, em algo que já foi dito, em algo que foi instituído, que foi estabelecido historicamente, assim, é só o trabalho de análise que pode dar visibilidade ao fato de que, na novidade, na contemporaneidade, algo de antigo, de fundador, de cristalizado se coloca.

${ }^{8}$ Freud (1972), ao descrever o funcionamento das formações inconscientes, afirma que o sonho é um dos modos de manifestação dessas formações, mas alerta para o fato de que há um impossível de dizer do sonho, que há "um umbigo do sonho" no qual não se chega, pois, ao contá-lo, estamos já na ordem da sua interpretação, portanto, há algo de para sempre perdido entre o sonho sonhado e o sonho contado.
} 
Para darmos visibilidade e caracterizarmos o que é da ordem do monumental/da monumentalidade, distinguindo as discursividades cristalizadas pelo político, das que se marcam pelo acontecimento discursivo, que põe em relação e que atualiza a história na língua, trazemos uma discussão sobre o Marco do Jauru, na cidade de Cáceres-MT, pois o marco apresenta/representa uma memória, um fato, um arquivo, que reverbera o que chamamos de monumental/de monumentalidade.

Como já dissemos, o monumental/a monumentalidade é um efeito produzido pelo documento tornado monumento, assim, qualquer objeto que se instaura por essa ordem faz funcionar discursividades do monumento e, por consequência, o que constitui o monumental/a monumentalidade, que diz da memória, do vivido, do acontecimento ou fato.

Dar a conhecer a monumentalidade do monumento é ler o objeto pelo interdiscurso, é colocá-lo em relação à história e ver o funcionamento das discursividades, ou seja, do monumental/da monumentalidade que o funda como monumento - material significante, uma vez que está/é investido pelo simbólico.

O Marco do Jauru é um monumento histórico, localizado no município de Cáceres-MT, sendo confeccionado em Lisboa, em pedra de Lioz $^{9}$. Foi trazido desmontado para o Brasil, sendo montado e instalado às margens do rio Jauru, em 18 de janeiro de 1754, pelo então Primeiro Governador e Capitão-General da Capitania de Mato Grosso, Dom Antônio Rolim de Moura Tavares. O Marco tinha por objetivo demarcar a fronteira territorial, estabelecida pelo Tratado de Madri, entre o domínio espanhol e o português na América do Sul, selando, assim, o fim das disputas territoriais entre Portugal e Espanha. Nessa direção, enquanto objeto criado para demarcar fronteira, o Marco é um documento/monumento que se estabelece como objeto de divisão, ou seja, funciona como um documento de fundação, de construção e de instalação de algo que se coloca para atestar uma divisão de fronteiras.

Desse modo, o Marco permaneceu às margens do rio Jauru por 129 anos, até que, por iniciativa do Tenente-Coronel Antônio Maria Coelho, quando foi transferido, em 02 de fevereiro de 1883, para o Largo da Matriz de Cáceres (hoje Praça Barão do Rio Branco), em frente à Catedral de São Luís, um movimento que o retira da função da simples fronteira, tornando-o monumental/monumentalizado para a cidade.

O Marco do Jauru arquiva, enquanto monumento, dois símbolos, dois poderes: 1) Portugal e Espanha enquanto dois países de igual poder que disputavam terras brasileiras, e, 2) um marco histórico, o Tratado de Madri, enquanto o acordo, o consenso a que chegaram os dois países sobre a divisão e a delimitação do território brasileiro, ou seja, o que o Tratado dispunha era sobre as terras que pertenciam a uma e a outra coroa - a portuguesa e a espanhola. Portanto, o monumento significava a disputa de duas importantes coroas sobre os seus territórios, em um momento em que o Brasil estava sob o jugo da coroa portuguesa. A colocação do Marco às margens do rio Jauru teve o

\footnotetext{
${ }^{9}$ Lioz ou pedra lioz é um tipo raro de calcário cuja maior ocorrência é Portugal, sendo abundantemente extraído nos arredores da vila de Pero Pinheiro, que fica no Conselho de Sintra, um dos dezesseis distritos que se situa a norte e noroeste de Lisboa. Sua principal tonalidade é o bege, mas pode variar para os tons de rosa claro com veios em lilás.
} 
propósito de representar, então, uma necessidade premente de demarcação do território brasileiro. Contudo, a primeira significação histórica do Marco do Jauru, a de demarcar a fronteira - ficou sobreposta pela implantação de dois novos tratados - o de El Pardo e de Santo Idelfonso ${ }^{10}$, respectivamente em 1.761 e 1.777.

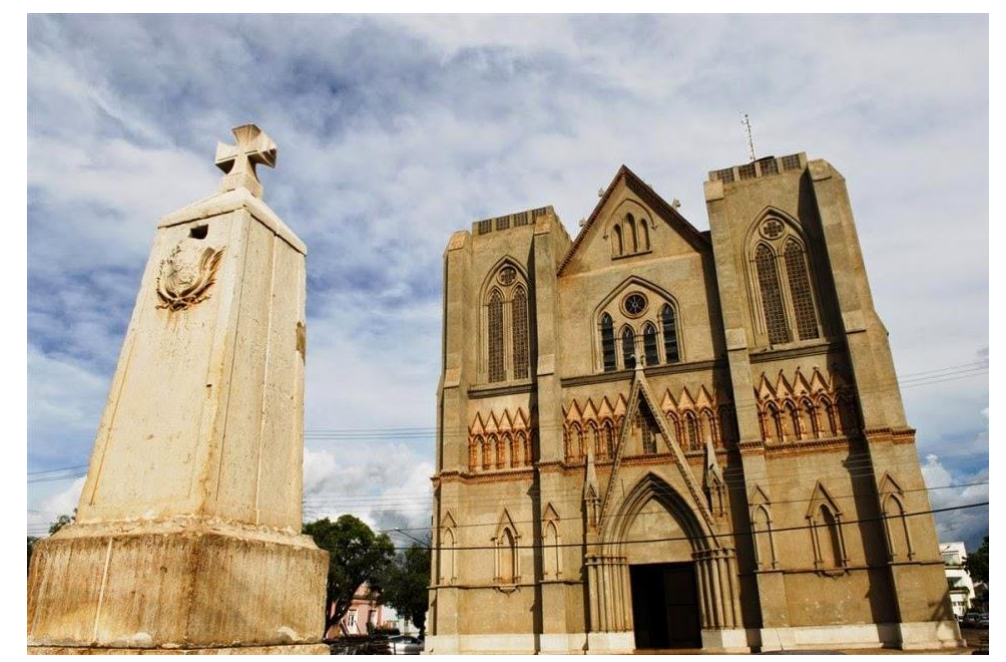

Figura 1. Marco do Jauru e Catedral de Cáceres. Foto: Plataforma Cáceres ${ }^{11 .}$

Dessa maneira, sem a função histórica que o instituiu, mas, ao mesmo tempo, carregando os sentidos de sua constitutividade, o Marco foi removido para o centro da cidade de Cáceres, em frente à Catedral, passando a compor o imaginário do morador, que, quase sempre desconhecendo a sua história de instituição, passou a atribuir-lhe outros sentidos, inclusive, o de um obelisco ligado à religião católica, portanto, à Catedral.

Ler o marco do Jauru discursivamente é dar visibilidade ao processo pelo qual se deu a demarcação de terras portuguesas e espanholas, e mais, o modo como os poderes instituídos do passado foram moldando e cristalizando seu sentido monumental, pois, segundo Le Goff (1990, p. 526), a "[...] análise do documento enquanto monumento permite à memória coletiva recuperá-lo e ao historiador usá-lo cientificamente, isto é, com pleno conhecimento de causa".

Porém, em Cáceres, o processo de remoção do Marco para uma área central da cidade, não representou, a não ser para o morador antigo e para os historiadores locais, que conheciam/conhecem a sua história de constituição, nenhuma ligação com a demarcação das fronteiras brasileiras. Em uma escuta informal que fizemos pela cidade, vimos o marco ser associado à igreja, a um ornamento da Praça Barão do Rio Branco, a

\footnotetext{
${ }^{10}$ O Tratado de El Pardo foi assinado em 1761 e tinha como objetivo anular o Tratado de Madri, de 1750, que objetivava redefinir as fronteiras entre a América Portuguesa e a Espanhola, anulando o que foi estabelecido no Tratado de Tordesilhas, de 1494. O Tratado de Santo Ildefonso foi um acordo assinado entre Portugal e Espanha, em 1777, e tinha como objetivo acabar com a disputa pela posse da Colônia de Sacramento, que passou a pertencer ao território espanhol no Tratado de El Pardo, mas com o novo tratado voltava para Portugal, assim como outras regiões na América do Sul entre as duas nações europeias na demarcação de fronteiras.

11 Disponível em http://plataformacaceres.blogspot.com.br/2014/04/catedral-de-sao-luiz-de-caceres-emarco.html. Acesso em 22/01/2016.
} 
um brinquedo de crianças etc. Ou seja, os sentidos do Marco como documento, como monumento, como uma edificação erigida para significar a fronteira se perdem, de modo que os novos sentidos assumidos pelo monumento é efeito do que estamos formulando como o seu caráter monumental/de monumentalidade.

Esse funcionamento, para nós como analistas de discurso, é efeito do fato de colocarmos os dizeres acerca do Marco na relação que ele tem com a história, o que faz com que a sua remoção para Cáceres não seja trivial, em razão da memória de constitutividade que ele carrega, assim, também não é trivial que o quartel, enquanto o espaço e a representação de um "batalhão na fronteira", entregue para os militares que são colocados na reserva, uma réplica do Marco, como uma honraria ao serviço prestado à soberania da nação brasileira.

É desse modo que, na Análise de Discurso, um objeto simbólico significa, ou seja, ao colocarmos um dado material em uma relação necessária com a história, portanto, com a memória que o constituiu/constitui, fazemos significar dizeres do passado que, no presente, dizem do instituído, do estabelecido, significando os sujeitos e os sentidos para a cidade. Os sentidos instituídos para Cáceres foi/é o de ser uma cidade criada para demarcar fronteiras, para garantir a soberania do Brasil, para assegurar a cisão da América do Sul, enfim, são sentidos que asseguram processos de identificação, uma vez que se constituem na relação da língua com a história, na relação de uma atualidade com a memória.

O funcionamento simbólico que instituiu/institui o que chamamos de monumental assegura um valor ${ }^{12}$ que garante a sobrevivência do Marco do Jauru, ou de qualquer monumento, enquanto objeto material que, ao dizer do vivido, da sua historicidade, significa, ao mesmo tempo, o hoje, o aqui e o agora $^{13}$, que, no entanto, não se desvincula da sua história de constitutividade. Nesse entendimento, a presença do Marco responde perguntas, colocando várias outras, assegura-lhe um valor que não é gratuitamente dado, como quer os historiadores. $\mathrm{O}$ valor dado ao monumento é resultado de uma construção que, de acordo com as acepções da própria palavra, está em constante processo de refazimento, significando e ressignificando o próprio objeto, a cidade, os sujeitos e os sentidos.

Desse modo, ler um objeto do passado, enquanto um arquivo, um monumento, é responder questões e estabelecer outras, é dar a conhecer os modos de individuação e de sua interpelação em sujeitos, é dar visibilidade ao poder instituído pelo político, que é instaurado pelo simbólico. É, pois, esse movimento que dá ao arquivo, ao monumento o sentido de monumental/de monumentalidade.

Lacerda (2009) apresenta uma discussão sobre o marco do Jauru, afirmando-o como o marco que ainda demarca, uma vez que se institui como um arcabouço de uma

\footnotetext{
12 Estamos tomando aqui a noção de valor tal como a institui Saussure (1995, p. 133): “[...] o valor [...] constitui [...] um elemento da significação, e é dificílimo saber como esta se distingue dele, apesar de estar sob sua dependência".

${ }^{13}$ Diferentemente dos epicuristas que pregavam a vivência do momento presente, desgarrado de qualquer raiz, o aqui e agora, para nós, não apaga a memória, que, constituída em outro tempo, em outro lugar, se carrega de ideologias que funcionam alheias à nossa vontade.
} 
memória ${ }^{14}$, visto que se instala como uma “[...] espécie de curinga, [que] serve para qualquer tipo de configuração no jogo do discurso identitário, [...] [uma] imagem agenciadora não apenas pelo poder político, mas também pelo capital". Ou seja, há, segundo o autor, uma configuração sobre o marco que não diz apenas do que é memorável, herdado, mas também do que se instituiu enquanto um monumento histórico que guarda o vivido, colocando questões no presente a partir do seu próprio trajeto de instituição e constituição.

Nessa direção, concordamos parcialmente com o autor, pois, para nós, o marco não serve a qualquer propósito no jogo identitário (por exemplo, o Marco ser relacionado à Igreja), pois o marco que ainda demarca só o faz por um jogo da memória que o coloca, na Praça Barão do Rio Branco da cidade de Cáceres-MT, como um marco que historicamente demarcou/demarca as terras brasileiras, daí sua identidade com a história de constituição da cidade, que, tal como o Marco, foi estrategicamente instituído pela coroa portuguesa para garantir as terras brasileiras.

Nesse entendimento, o Marco demarca para quem conhece/desconhece a história da cidade, assegurando, ao mesmo tempo, o seu caráter documental e aquilo que ele pode ainda significar para o morador local, ou seja, o que o entorno permite, enquanto contexto imediato. Assim, na praça da igreja, o Marco é interpretado como um monumento religioso ou como brinquedo (escorregador para as crianças).

Desse modo, não é da ordem de um não sentido que o Marco se localize no centro histórico da cidade, como também não o é o fato de uma réplica sua ser entregue a cada militar do $2^{\circ}$ BFRON (Batalhão de Fronteira), quando no fim da carreira, pois o gesto simbólico que ele representa é o de um reconhecimento ao serviço prestado à preservação de uma dada fronteira brasileira pelos militares, tal como o Marco representou/representa, pois os militares, como nenhum outro morador, conhecem o monumento enquanto documento e o tempo e os fatos que ele significou na história.

Nesse jogo discursivo, vemos o Marco, funcionando como aquilo que é "digno de memória" (ZANCARINI, 2006), se marcar também pelo discurso do turismo, uma vez que a cidade, dadas as belezas naturais e históricas que encerra, é considerada como polo turístico do Estado. Assim, trazer para o seu centro histórico um obelisco, de importância também histórica, é, além de carregar o monumento dos sentidos de identificação com uma cidade criada para ser fronteira, marcá-lo pelo ideal histórico e político de sua implantação - movimentos que o tomam como atrelado também ao discurso turístico.

Nessa direção, vemos no gesto de o Município se apropriar do marco, a instauração de sentidos novos, de novas simbolizações, que, contudo, não se desvinculam ou não apagam as antigas ou até as equivocadas acerca do objeto. São, pois, sentidos simbólicos, que, atribuídos ao Marco, o fazem instituir-se pela ordem do monumental.

\section{Algumas considerações}

\footnotetext{
${ }^{14}$ Para Lacerda (2009), houve grandes fatos históricos que marcaram o Brasil-colônia, como a demarcação de terras, a partir dos bandeirantes - período essencial para compreensão e criação da história de Mato Grosso e seus municípios.
} 
Como já dissemos, o Marco, dados os seus sentidos históricos, foi plantado à margem esquerda do Rio Jauru, mas, em 2 de fevereiro de 1883, foi removido dali e implantado no Largo da Matriz, hoje Praça Barão do Rio Branco, em frente à Catedral de São Luís, em Cáceres. Nesse gesto, os novos sentidos dados ao Marco não apagaram/apagam, não silenciaram/silenciam o seu processo de significação, pois o que permanece, ainda que a maior parte dos moradores atuais desconheça a sua história, são os sentidos monumentais de sua constituição, ou seja, é a natureza monumental, portanto, simbólica do objeto, pois o Marco se marca, tal qual a cidade, por uma história de fronteira, de demarcação, de limites, de território/de territorialidade, que dizem das terras brasileiras e da soberania de um povo e de uma nação.

Orlandi (2010, p. 11,12), ao tratar do funcionamento da estátua de Fernão Dias Paes, em Pouso Alegre-MG, afirma que ela é uma

[...] rede de sentidos [na qual] se enredam a memória e os acontecimentos. O Estado, o indivíduo e a sociedade. Em uma relação que é política. [...] O que fica significado [...] não começa nem termina em Pouso Alegre. Mas que por estar ali é um marco de territorialidade. A que assenta os [moradores] [...] não apenas num solo, mas numa memória, e, por ela, em uma história oficial, a que se conta, a que se ensina e que se aprende. E que afeta ideologicamente o habitante do lugar mesmo que ele não saiba. [...] A estátua é o gesto de memória que ao individuar o sujeito pousoalegrense o faz habitante singular de uma unidade territorial mais vasta: a do Brasil em Minas.

Na mesma direção do que diz a autora, o Marco do Jauru é, a um só tempo, memória e acontecimento discursivo, é fronteira do país e memória da cidade de CáceresMT, pois ambos, o Marco e a cidade, se instalam como territórios, como espaços que delimitam fronteiras. Nessa direção, o monumento diz do sujeito morador da cidade, pois o individua no sentido de torná-lo parte de sua história de significação.

\section{Referências bibliográficas}

ACERDA, R. G. Os artesãos da memória nas tramas e retramas da história: identidade e memória em Cáceres no limiar do século XXI. Dissertação. Mestrado em História, Programa de Pós-graduação em História, UFMT, Cuiabá-MT, 2009.

BORGES, A.A.C. Arquivo e memória: observações teóricas e analíticas em "flagrantes" na cidade. Em: BRESSANIN, J.A.; ZATTAR, N.; KARIN, T.M.; DI RENZO, A.M. (Orgs.). Linguagem e interpretação: a institucionalização dos dizeres na história. Campinas: Ed. RG; Cáceres (MT): Ed. da Unemat, 2013. p. 43-60.

FOUCALT, M. A Arqueologia do Saber. Trad. Bras. Rio de Janeiro: Forense, 2008.

FREUD, S. A interpretação dos sonhos e sobre os sonhos. Rio de Janeiro: Imago, 1972.

LAGAZZI. S. Linha de passe: a materialidade significante em análise. RUA, Campinas, SP, $\mathrm{n}^{\mathrm{o}} 16$, v. 2, 173-182, nov. 2010. 
O recorte significante na memória. Apresentação de Comunicação no III SEAD [Seminário de Estudos em Análise do Discurso], Porto Alegre, 2007. Disponível em http://anaisdosead.com.br/3SEAD/Simposios/SuzyLagazzi.pdf. Acesso em 15/06/ 2015.

LE GOFF, J. História e memória. Trad. Bras. Campinas, SP: Ed. da Unicamp, 1990.

RODRIGUES, C.M. Cidade, monumentalidade e poder. GEOgraphia, América do Norte, 3, set. 2009.

ORLANDI, E.P. Discurso em análise: sujeito, sentido e ideologia. Campinas: Pontes, 2012.

Os sentidos de uma estátua: espaço, individuação, acontecimento e memória. Entremeios, Revista de Estudos do Discurso, v.1, n.1, jul/2010. Disponível em http://www.entremeios.inf.br/published/1.pdf. Acesso em jan. de 2016.

Análise de Discurso: princípios e procedimentos. 3ª ed. Campinas: Pontes, 2001.

PÊCHEUX, M. Papel da Memória. Em: ACHARD, P. et al. Papel da memória. Trad. Bras. Campinas, SP: Pontes Editores, 1999. p. 49-56.

O discurso: estrutura ou acontecimento. $2^{\text {a }}$. ed. Campinas: Pontes, 1997.

Delimitações, inversões, deslocamentos. Cad. Est. Ling., Unicamp, 1990.

. Semântica e discurso: uma crítica à afirmação do óbvio. Campinas: Ed. da Unicamp, 1988.

ZANCARINI, J.-C. La Politisation de la Mémoire: les 'choses dignes de mémoire' chez Machiavel et Francesco Guicciardini. Mémoire et subjectivité (XIVe-XVIIe siècle), Paris, 2006. p. 41-50.

Artigo recebido em: dezembro de 2016.

Aprovado e revisado em: fevereiro de 2017.

Publicado em: abril de 2017.

\section{Para citar este texto:}

BINDANDI, Welliton Martins; MALUF-SOUZA, Olimpia. O Marco do Jauru: a construção de um saber sobre o monumento/a monumentalidade. Entremeios [Revista de Estudos do Discurso, on-line], Seção Estudos, Programa de Pós-Graduação em Ciências da Linguagem (PPGCL), Universidade do Vale do Sapucaí (UNIVÁS), Pouso Alegre (MG), vol. 14, p. 37-50, jan. - jun. 2017.

DOI: http://dx.doi.org/10.20337/ISSN2179-3514revistaENTREMEIOSvol14pagina37a50 